\title{
ESTUDO DA ESTABILIDADE QUÍMICA E MICROBIOLÓGICA DO SUCO DE CAJU IN NATURA ARMAZENADO EM DIFERENTES CONDIÇÕES DE ESTOCAGEM ${ }^{1}$
}

\author{
Flávia Conde LAVINAS², Natália Correa de ALMEIDA², Marco Antonio Lemos MIGUEL ${ }^{3}$, \\ Maria Lúcia Mendes LOPES ${ }^{2}$, Vera Lúcia VALENTE-MESQUITA ${ }^{2, *}$
}

\begin{abstract}
RESUMO
O caju, rico em nutrientes, apresenta alta perecibilidade. Este trabalho teve como objetivo avaliar a estabilidade química, físicoquímica e microbiológica do suco de caju in natura mantido em temperatura ambiente por $24 \mathrm{~h}$, estocado sob refrigeração por sete dias e sob congelamento por 120 dias. O teor de ácido ascórbico no suco recém-extraído foi de $147,29 \pm 0,41 \mathrm{mg} / 100 \mathrm{~mL}$ e reduziu em $6,57 \%$ em temperatura ambiente. Durante a estocagem sob refrigeração e congelamento, as taxas de redução dessa vitamina foram $1,16 \%$ ao dia e $0,05 \%$ ao dia, respectivamente. Foi observado aumento na contagem de bactérias mesófilas totais e fungos filamentosos e leveduras no suco mantido em temperatura ambiente. Nos sucos estocados sob refrigeração durante sete dias houve redução da contagem de bactérias mesófilas totais e aumento na contagem de fungos filamentosos e leveduras. Nos sucos congelados, a contagem de fungos filamentosos e leveduras permaneceu inferior à inicial, enquanto a de bactérias mesófilas totais apresentou variação até o trigésimo dia. A partir deste período, esta permaneceu estável em menos de um ciclo logarítmico acima da contagem inicial. Nos períodos estudados, refrigeração e congelamento mostraram-se eficazes na preservação do ácido ascórbico e da qualidade microbiológica do suco de caju in natura.
\end{abstract}

Palavras-chave: suco de caju in natura, ácido ascórbico, qualidade microbiológica, estocagem.

\section{SUMMARY}

STUDY OF THE CHEMICAL AND MICROBIOLOGICAL STABILITY OF CASHEW APPLE JUICE IN DIFFERENT STORAGE CONDITIONS. Cashew apple, which is rich in nutrients, is highly perishable. The objective of the present study was to evaluate the chemical, physicochemical and microbiological stability of cashew apple juice kept at room temperature for $24 \mathrm{~h}$, refrigerated for seven days or frozen for 120 days. The ascorbic acid content in fresh cashew apple juice was $147.29 \pm 0.41 \mathrm{mg} / 100 \mathrm{~mL}$ and decreased $6.57 \%$ when kept under room temperature. In the juices stored when refrigerated and when frozen, a reduction rate of ascorbic acid was $1.16 \% /$ day and $0.05 \% /$ day, respectively. The chemical and physicochemical parameters remained stable. In the juice kept at room temperature, an increase in the count of mesophile bacteria and yeasts and moulds was observed. In the juices stored when refrigerated for seven days, mesophile bacteria counts decreased and yeast and mould counts increased. In the frozen juices, the yeast and mould counts remained lower than the initial counts, while mesophile bacteria showed variation until the thirtieth day and remained stable in less than one logarithmic cycle above the initial count. Throughout the study period, refrigeration and freezing were efficient for ascorbic acid and microbiological quality preservation of the cashew apple juice.

Keywords: cashew apple juice, ascorbic acid, microbiological quality, storage.

\section{1 - INTRODUÇÃO}

A cultura do caju (Anacardium occidentale, L) é considerada a de maior importância socioeconômica da região Nordeste do Brasil, em decorrência dos produtos industrializados oriundos do fruto e do pseudofruto [28].

Botanicamente, a verdadeira fruta do cajueiro é a castanha, uma amêndoa envolvida por uma casca dura; enquanto o pedúnculo (pseudofruto ou "maçã"), conhecido como caju, apresenta estrutura semelhante a uma fruta, fibrosa, suculenta, rica em vitamina C [17, 37].

O caju apresenta em sua composição vitaminas, taninos, sais minerais, ácidos orgânicos e carboidratos, constituin-

\footnotetext{
${ }^{1}$ Recebido para publicação em 27/3/2006. Aceito para publicação em 20/10/2006 (001704)

${ }^{2}$ Centro de Ciências da Saúde, Instituto de Nutrição Josué de Castro,

Universidade Federal do Rio de Janeiro, Avenida Bauhinia, 400,

Bloco J, Ilha da Cidade Universitária, CEP 21941-590,

Rio de Janeiro (RJ), Brasil,

E-mail:valentem@nutricao.ufrj.br

${ }^{3}$ Instituto de Microbiologia Professor Paulo de Góes,

Universidade Federal do Rio de Janeiro.

* A quem a correspondência deve ser enviada
}

do-se como uma importante fonte nutricional. Entretanto, esses componentes contribuem também para sua elevada perecibilidade, sendo necessários, cuidados especiais na estocagem, transporte e processamento [38].

O caju é uma importante fonte de vitamina C - também denominada ácido ascórbico (AA) -, nutriente que participa em vários processos metabólicos do organismo, dentre eles, formação de colágeno e ácidos biliares, inativação de radicais livres, aumento da absorção do ferro da dieta e fortalecimento do sistema imunológico [3].

O AA presente em sucos de frutas pode ser oxidado, dependendo das condições de estocagem do suco [24]. Devido à sua instabilidade, o AA tem sido utilizado como indicador da qualidade nutricional de frutas e vegetais [35]. É importante que o consumidor conheça a melhor forma de armazenar sucos de frutas, para que possa aproveitar ao máximo seu conteúdo de vitamina C [24].

A escassez de estudos sobre a estabilidade microbiológica de produtos de origem vegetal pode ser atribuída ao fato de estes serem considerados menos propícios à ação microbiana do que os alimentos de origem animal [50]. A 
acidez dos frutos cítricos inibe o crescimento da maioria dos microrganismos patogênicos, permitindo, porém, o desenvolvimento de bactérias láticas, leveduras e fungos filamentosos, cujo metabolismo produz substâncias indesejáveis [14].

Refrigeração e congelamento são métodos adequados para a conservação de sucos de frutas, contribuindo positivamente, tanto microbiológica quanto nutricionalmente, para a manutenção de alimentos seguros e estáveis [18, 46].

Alguns trabalhos avaliam o teor de AA em polpa de caju e sucos de caju in natura e industrializados [2, 7, 28, 34]. No entanto, não foram encontrados estudos que avaliem tanto a estabilidade deste nutriente quanto a estabilidade microbiológica no suco de caju in natura. Este trabalho teve como objetivo, avaliar a estabilidade química, físico-química e microbiológica do suco de caju in natura, submetido a diferentes condições de estocagem.

\section{2 - MATERIAIS E MÉTODOS}

\section{1 - Materiais}

Trinta quilos de caju in natura foram obtidos no mercado atacadista da cidade do Rio de Janeiro e transportados para o Laboratório de Análise e Processamento de Alimentos - Universidade Federal do Rio de Janeiro/UFRJ. As frutas foram selecionadas, descastanhadas, lavadas e imersas em solução de hipoclorito de sódio a $100 \mathrm{ppm}$ por $15 \mathrm{~min}$. O suco foi extraído em despolpadeira (Tomasi), previamente higienizada por vapor d'água, e subdividido em alíquotas e subalíquotas para as diferentes análises e tempos de análises, respectivamente. Uma alíquota foi analisada imediatamente após a extração do suco, enquanto as demais foram acondicionadas em garrafas de vidro estéreis, envoltas em papel alumínio, para impedir a incidência de luz, e estocadas nas seguintes condições: $24 \mathrm{~h} /$ temperatura ambiente (21 a $25^{\circ} \mathrm{C}$ ); durante sete dias, sob refrigeração $\left(4 \pm 1{ }^{\circ} \mathrm{C}\right)$; e, durante 120 dias, sob congelamento $\left(-22^{\circ} \mathrm{C} \pm 1{ }^{\circ} \mathrm{C}\right)$. As alíquotas foram submetidas às análises químicas, físicoquímicas e microbiológicas.

\section{2 - Métodos}

\subsection{1 - Análises químicas e físico-químicas}

O teor de AA foi determinado em triplicata, por titulação com 2,6 diclorofenolindofenol [6], modificado por BENASSI \& ANTUNES [9]. Os resultados foram expressos em $\mathrm{mg}$ de AA por $100 \mathrm{~mL}$ de amostra. As amostras foram centrifugadas por $10 \mathrm{~min}$, a $3000 \mathrm{rpm}$, antes das análises, para facilitar a visualização do ponto de viragem.

Foram realizadas análises em triplicata, para determinação da acidez total titulável (ATT), expressa em ácido cítrico anidro\%, por titulação com $\mathrm{NaOH}$ a $0,1 \mathrm{~N}$; do teor de sólidos solúveis totais (SST), expressos em ${ }^{\circ} \mathrm{Brix}$, em refratômetro Eppendorf 2763; e do pH, em potenciômetro digital Micronal, de acordo com as Normas Analíticas do Instituto Adolf Lutz [21].

\subsection{2 - Análises Microbiológicas}

Alíquotas de $10 \mathrm{~mL}$ de suco de caju in natura foram diluídas serialmente em água peptonada estéril $(0,1 \%)$ para pesquisa, em duplicata, de bactérias mesófilas totais, em ágar padrão para contagem (APC); de bactérias láticas, em ágar Man, Rogosa, Sharpe (MRS); de fungos filamentosos e leveduras, em ágar batata dextrose (ABD) $\mathrm{pH} 3,5$, acidificado com ácido tartárico $10 \%$, todos semeados em superfície [10]. Os resultados foram expressos em logaritmo (Log) de unidades formadoras de colônias (UFC) por mL.

\subsection{3 - Análises Estatísticas}

Os resultados obtidos foram submetidos à análise de regressão [25]. O software estatístico utilizado foi o Excel 2000 (Microsoft Corporation).

\subsection{4 - Reagentes}

Todos os meios de cultura e reagentes utilizados para a realização das análises foram procedentes da Merck.

\section{3 - RESULTADOS E DISCUSSÃO}

\section{1 - Validação do método titulométrico para suco de caju in natura}

A determinação de AA em sucos de frutas por titulação com 2,6-diclorofenolindofenol é a metodologia recomendada pela Associação Oficial de Análises Químicas [6] e existem vários trabalhos publicados que empregam esta metodologia para determinar o teor desta vitamina em sucos de frutas $[4,7,12,20,28,31,33,43]$.

Com o objetivo de verificar a linearidade da curva de calibração da determinação de AA, foram realizadas análises de soluções padrão de AA, preparadas pela diluição seriada de uma solução estoque contendo 60 mg de AA /100 mL. Os resultados da análise de correlação de Pearson entre as concentrações determinadas por análise e as concentrações reais são apresentadas na Figura 1 . O coeficiente de correlação foi 0,9999 , significativo ao nível de $0,1 \%$. A equação da regressão linear apresentou valores de intercepção e de declividade iguais a 0,028 e 1 , respectivamente. Os resultados indicaram forte correlação positiva entre as concentrações de AA determinadas por análise e reais.

Quantidades conhecidas de solução padrão de AA (10 a $50 \mathrm{mg} / 100 \mathrm{~mL}$ de suco) foram adicionadas ao suco de caju in natura e a recuperação foi testada utilizando o método titulométrico em seis replicatas. Os dados, apresentados na Tabela 1, indicam exatidão na determinação do AA.

Os resultados de ambos os experimentos ratificam a exatidão do método titulométrico na determinação de AA em 


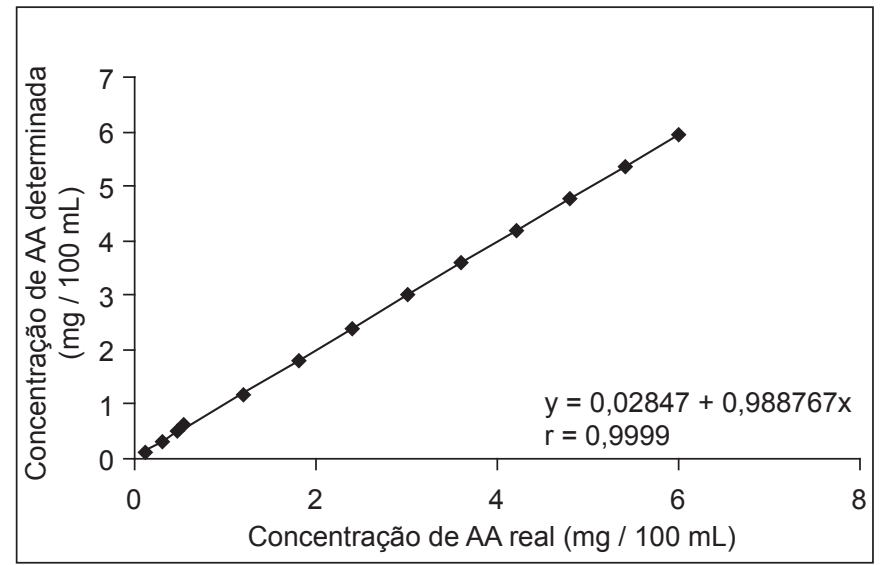

FIGURA 1 - Correlação entre as concentrações reais de ácido ascórbico (x) e as determinadas pelo método titulométrico de Tillmans (y).

TABELA 1 - Recuperação de ácido ascórbico em suco de caju in natura.

\begin{tabular}{|c|c|c|c|}
\hline \multirow{2}{*}{$\begin{array}{c}\text { Suco de caju } \\
\text { in natura }\end{array}$} & \multicolumn{3}{|c|}{ Ácido Ascórbico (AA) } \\
\hline & $\begin{array}{l}\text { Adicionado } \\
\text { ( } \mathrm{mg} / 100 \mathrm{~mL})\end{array}$ & $\begin{array}{c}\text { Determinado } \\
\text { por análise } \\
(\mathrm{mg} / 100 \mathrm{~mL})^{*}\end{array}$ & $\begin{array}{c}\text { Percentual de } \\
\text { recuperação } \\
(\%)\end{array}$ \\
\hline \multirow[t]{6}{*}{133,75} & 0 & 133,75 & 100,00 \\
\hline & 10 & 145,00 & 100,90 \\
\hline & 20 & 156,25 & 101,90 \\
\hline & 30 & 166,25 & 101,90 \\
\hline & 40 & 176,25 & 101,90 \\
\hline & 50 & 185,42 & 101,20 \\
\hline
\end{tabular}

*Média de seis repetições.

suco de caju in natura, bem como comprovam a qualidade dos reagentes utilizados.

3.2 - Variação do teor de AA em suco de caju armazenado em diferentes tempos e condições de estocagem

Neste experimento, o teor médio de AA no suco de caju recém extraído foi de 147,29 0,41 mg/100 mL.

Dados da literatura mostram grande variação no teor de AA em suco de caju [ $1,7,22,29,45,46,48]$. Tal variação pode ser atribuída a diversos fatores, tais como tipo de solo, época da colheita, forma de cultivo, clima, tipo de caju e procedimento de armazenagem. Alguns estudos mostram diferenças na composição de nutrientes entre frutas cultivadas em diferentes regiões [7, 36].

De acordo com MAIA \& SOARES [29], o caju apresenta grande variabilidade quanto ao conteúdo de AA, tendo sido encontrado o valor máximo de 387,0 mg/100 g e mínimo de $156,0 \mathrm{mg} / 100 \mathrm{~g}$, para cajus colhidos em um mesmo pomar. OLIVEIRA et al. [34] observaram que o teor de AA em polpa de caju também variou consideravelmente, entre 76,95 e $228,02 \mathrm{mg} / 100 \mathrm{~g}$.

Os resultados de teor de AA em sucos de diferentes frutas demonstram que, comparativamente, o suco de caju apresenta teor mais elevado desta vitamina [1, 30, 41, 43, 49]. Desta forma, é possível confirmar que o suco de caju é uma importante fonte de AA, apresentando teores superiores aos dos outros sucos considerados como fontes desta vitamina, como os de laranja e limão.

Com base nos resultados do presente estudo e com o objetivo de verificar o volume de suco de caju in natura necessário para suprir os valores de referência de ingestão diária [16] de vitamina $\mathrm{C}$ por faixa etária, sexo e estado fisiológico, foi elaborada a Tabela 2 .

TABELA 2 - Volume de suco de caju in natura diluído necessário para atingir a RDI* de vitamina C por faixa etária, sexo e estado fisiológico.

\begin{tabular}{|c|c|c|c|}
\hline $\begin{array}{c}\text { Faixa etária/ } \\
\text { sexo/estado } \\
\text { fisiológico }\end{array}$ & $\begin{array}{c}\text { RDI } \\
\mathrm{mg} / \mathrm{dia}\end{array}$ & $\begin{array}{l}\text { Volume de } \\
\text { suco necessá- } \\
\text { rio para atingir } \\
\text { a RDI (mL) }\end{array}$ & $\begin{array}{l}\text { Volume de } \\
\text { refresco de } \\
\text { caju (diluição } \\
\text { 1:3) necessário } \\
\text { para atingir a } \\
\text { RDI (mL) }\end{array}$ \\
\hline \multicolumn{4}{|l|}{ Crianças } \\
\hline $0-6$ meses & 40 & 27,16 & 81,47 \\
\hline $7-12$ meses & 50 & 33,95 & 101,84 \\
\hline $1-3$ anos & 15 & 10,18 & 30,55 \\
\hline 4-8 anos & 25 & 16,97 & 50,92 \\
\hline \multicolumn{4}{|l|}{ Mulheres } \\
\hline 9-13 anos & 45 & 30,55 & 91,66 \\
\hline $14-18$ anos & 75 & 50,92 & 152,76 \\
\hline 19->70 anos & 90 & 61,10 & 183,31 \\
\hline \multicolumn{4}{|l|}{ Homens } \\
\hline $9-13$ anos & 45 & 30,55 & 91,66 \\
\hline $14-18$ anos & 65 & 44,13 & 132,39 \\
\hline $19->70$ anos & 75 & 50,92 & 152,76 \\
\hline \multicolumn{4}{|l|}{ Gestantes } \\
\hline$\leq 18$ anos & 80 & 54,31 & 162,94 \\
\hline $19-50$ anos & 85 & 57,71 & 173,13 \\
\hline \multicolumn{4}{|l|}{ Lactantes } \\
\hline$\leq 18$ anos & 115 & 78,08 & 234,23 \\
\hline $19-50$ anos & 120 & 81,47 & 244,42 \\
\hline
\end{tabular}

*Referência de ingestão diária.

O volume de suco de caju necessário para atingir a RDI em diferentes faixas etárias, estados fisiológicos e sexos variou de 10 a $81 \mathrm{~mL}$. Para ser consumido, o suco de caju, normalmente, é diluído, sendo oferecido sob a forma de refresco. Considerando a diluição de 1:3 (uma parte de suco mais duas partes de água), o volume necessário de refresco seria de, aproximadamente, 30 a $240 \mathrm{~mL}$. Para o grupo etário de 4 a 8 anos, um volume de $51 \mathrm{~mL}$ de refresco é suficiente para atender ao valor de referência. Em termos nutricionais, este fato é importante, uma vez que nesta faixa de idade é comum o consumo de bebidas industrializadas de baixo valor nutricional, que fornecem calorias vazias e contêm conservantes químicos.

A necessidade de ingestão de vitamina $\mathrm{C}$ é mais elevada na fase de aleitamento e pode ser suprida pela ingestão diária de aproximadamente um copo de refresco de caju. Estes dados comprovam que o caju é uma importante fonte desta vitamina e pode ser recomendado na prevenção da sua deficiência. 
A Figura 2 apresenta a variação do teor AA em suco de caju mantido em temperatura ambiente $\left(23^{\circ} \mathrm{C}\right)$ por $24 \mathrm{~h}$ e armazenado sob refrigeração $\left(2{ }^{\circ} \mathrm{C}\right)$ durante sete dias e sob congelamento $\left(-22^{\circ} \mathrm{C}\right)$ por até 120 dias. Os símbolos representam os dados experimentais e as linhas, as equações obtidas por análise de regressão.

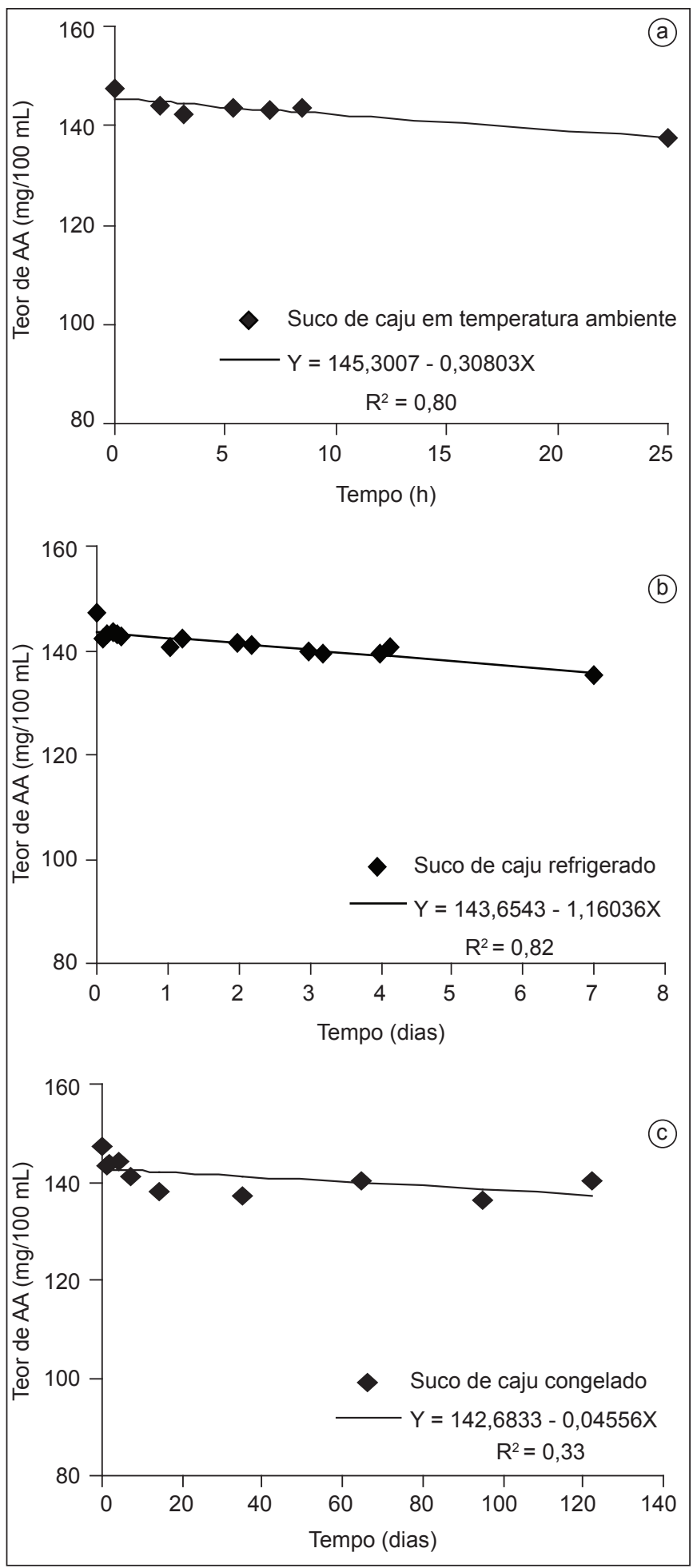

FIGURA 2 - Variação do teor médio de ácido ascórbico (AA) em suco de caju in natura mantido em temperatura ambiente $\left(23^{\circ} \mathrm{C}\right)$ durante $24 \mathrm{~h}$ (a) e armazenado sob refrigeração $\left(2{ }^{\circ} \mathrm{C}\right)$ por sete dias (b) e sob congelamento $\left(-22^{\circ} \mathrm{C}\right.$ ) por 120 dias (c).
Houve redução no teor médio de AA de $6,57 \%, 4,44 \%$ e $2,70 \%$, respectivamente, nos sucos armazenados em temperatura ambiente, sob refrigeração ou sob congelamento durante $24 \mathrm{~h}$. Este resultado está de acordo com aqueles obtidos por outros pesquisadores com diferentes frutas. ZERDIN et al. [51], avaliando a estabilidade do AA em suco de laranja concentrado, observaram que a perda deste nutriente foi significativamente maior no suco armazenado a $25{ }^{\circ} \mathrm{C}$ do que naquele mantido a $4{ }^{\circ} \mathrm{C}$. Da mesma forma, NAGY \& SMOOT [32] verificaram um aumento significativo na taxa de degradação de AA em sucos de laranja estocados durante 84 dias entre 22 a $26{ }^{\circ} \mathrm{C}$ quando comparado ao suco armazenado a $4{ }^{\circ} \mathrm{C}$. SASTRY et al., citado por TELLES [47], estudando o teor de AA em sucos de caju clarificado e pasteurizado, observaram uma perda de 29 a 53\% à temperatura ambiente ao fim de 32 semanas, respectivamente. VEIGA et al. [49], analisando a estabilidade do AA em suco de limão galego por $24 \mathrm{~h}$, observaram perda de 24,56\% para o suco armazenado a $23{ }^{\circ} \mathrm{C}$ e de $0,66 \%$ para o suco armazenado a $2{ }^{\circ} \mathrm{C}$.

No suco de caju mantido sob refrigeração por sete dias, o percentual de perda foi de $8,12 \%$, com taxa de redução de $1,16 \%$ ao dia. JOHNSTON \& BOWLING [23] relataram perda de AA de aproximadamente $2 \%$ por dia em suco de laranja armazenado sob refrigeração, enquanto OLIVEIRA et al. [33] observaram perda de $0,5 \%$ de AA em suco de laranja Pêra armazenado sob refrigeração por 25 dias. Resultados diferentes foram encontrados por SILVA [43] para suco de laranja Pêra, no qual o AA se manteve estável durante sete dias sob refrigeração.

O suco de caju armazenado sob congelamento por 120 dias apresentou uma taxa de redução de AA de 0,05\% ao dia. CAMPELO et al. [12] avaliaram a estabilidade química do AA em polpa congelada de acerola e observaram redução de 38,04\% desta vitamina após 365 dias de armazenamento. LEE \& COATES [26] observaram uma perda de $0,34 \%$ ao mês deste nutriente em amostras de suco de laranja natural congelado, enquanto PEDRÃO et al. [39] não observaram redução significativa no teor de AA em suco de limão armazenado sob congelamento por 60 dias. De acordo com CORREAA NETO \& FARIA [14], a temperatura de estocagem é considerada o fator mais importante na estabilidade $\mathrm{e}$ qualidade dos sucos cítricos.

A redução do teor de AA em sucos pode ser de natureza oxidativa e pode alterar sensivelmente as características nutricionais do produto. Estas alterações dependem das condições de processamento utilizadas, da presença de $\mathrm{O}_{2}$, da embalagem utilizada, da relação tempo/temperatura de estocagem, além da incidência da luz [14].

\subsection{3 - Parâmetros químicos e físico-químicos}

Os resultados das análises dos parâmetros químicos e físico-químicos (ATT, pH e SST) do suco de caju in natura armazenado em diferentes condições de estocagem estão apresentados na Tabela 3 . 
TABELA 3 - Valores médios de ATT, pH e SST de suco de caju in natura mantido em temperatura ambiente (TA) por 24 h e armazenado sob refrigeração (R) por sete dias e sob congelamento (C) por 120 dias.

\begin{tabular}{|c|c|c|c|c|c|c|c|c|c|}
\hline Tempo & \multicolumn{3}{|c|}{$\begin{array}{c}\text { ATT } \\
\text { (ácido cítrico \%)* }\end{array}$} & \multicolumn{3}{|c|}{$\mathrm{pH}^{*}$} & \multicolumn{3}{|c|}{ SST $\left({ }^{\circ}\right.$ Brix) ${ }^{*}$} \\
\hline $\mathrm{Oh}$ & 0,46 & 0,46 & 0,46 & 4,27 & 4,27 & 4,27 & 11,17 & 11,17 & 11,17 \\
\hline $6 \mathrm{~h}$ & 0,50 & 0,53 & - & 4,31 & 4,30 & - & 11,17 & 11,17 & - \\
\hline $10 \mathrm{~h}$ & 0,45 & 0,54 & - & 4,40 & 4,32 & - & 11,33 & 11,50 & - \\
\hline $1 \mathrm{dia}$ & 0,39 & 0,50 & 0,51 & 4,28 & 4,30 & 4,28 & 11,17 & 11,17 & 11,00 \\
\hline 2,5 dias & - & 0,52 & - & - & 4,30 & - & - & 11,00 & - \\
\hline 3 dias & - & 0,48 & - & - & 4,34 & - & - & 11,00 & - \\
\hline 3,5 dias & - & 0,48 & - & - & 4,31 & - & - & 11,17 & - \\
\hline 4 dias & - & 0,49 & 0,51 & - & 4,31 & 4,33 & - & 11,17 & 11,00 \\
\hline 4,5 dias & - & 0,51 & - & - & 4,31 & - & - & 11,17 & - \\
\hline 90 dias & - & - & 0,52 & - & - & 4,25 & - & - & 11,00 \\
\hline 120 dias & - & - & 0,51 & - & - & 4,32 & - & - & 11,67 \\
\hline
\end{tabular}

A acidez é um importante parâmetro na avaliação do estado de conservação de um alimento. Geralmente, o processo de decomposição de um alimento, seja por hidrólise, oxidação ou fermentação, altera a concentração dos íons de hidrogênio e, por conseqüência, sua acidez [21]. A acidez inicial do suco de caju foi de $0,46 \%$. Este valor é semelhante ao encontrado por SOUZA FILHO et al. [46] $(0,47 \%$ a $0,49 \%$ ), superior ao encontrado por INYANG \& ABAH [22], $(0,29 \%)$ e inferior aos relatados por MAIA [27] e AKINWALE, OLUBAMIWA \& AJAV [2], ambos de 0,67\%. OLIVEIRA et al. [34], avaliando os parâmetros de qualidade de polpas de frutas, mostrou que a polpa que apresentou menor valor de acidez, foi a que teve menor teor de AA. Contudo, mesmo que esta variação seja direta, não é linear, o que indica a presença de outros ácidos.

A determinação do pH em um alimento é importante devido a sua influência na palatabilidade, no desenvolvimento de microrganismos, na escolha da temperatura do tratamento térmico, na seleção dos produtos de higienização e de aditivos, entre outros [13].

O valor inicial de $\mathrm{pH}(4,27)$, encontrado no suco de caju in natura, coincidiu com os relatados por MAIA [27], INYANG \& ABAH [22], SOUZA FILHO et al. [46], ASSUNÇÃO \& MERCADANTE [7] e AKINWALE, OLUBAMIWA \& AJAV [2], que variaram de 3,80 a 4,50. BELITZ \& GROSCH [8] relataram a maior suscetibilidade do AA ao meio alcalino.

O teor de SST é utilizado como indicador de maturidade para alguns frutos e indica a quantidade de substâncias, na maior parte açúcares, que se encontram dissolvidas no suco [5]. De acordo com GOMES, FIGUEIREDO \& QUEIROZ [19], os principais açúcares presentes em frutas são a glicose, a frutose e a sacarose em proporções variadas, de acordo com a espécie. O teor de açúcares aumenta com a maturação do fruto.

O teor inicial de SST do suco de caju foi de $11,17^{\circ} \mathrm{Brix}$ e está de acordo com dados da literatura que mostram uma variação de $8,0^{\circ}$ Brix a $12,6{ }^{\circ} \mathrm{Brix}[2,7,22,27,46]$.

Os valores médios de ATT, SST e pH do suco de caju permaneceram estáveis durante todo o período de armazenamento, nas diferentes condições de estocagem.

\section{2 - Análises microbiológicas}

A legislação brasileira em vigor [11] não estabelece padrões para a contagem de bactérias mesófilas totais e fungos filamentosos e leveduras para sucos de frutas. No entanto, a pesquisa de bactérias mesófilas totais tem sido usada como indicador da qualidade higiênico-sanitária dos alimentos [42]. A presença destes microrganismos em grande número indica matéria-prima excessivamente contaminada, limpeza e desinfecção de superfícies inadequadas, higiene insuficiente na produção e condições impróprias de tempo e temperatura durante a conservação dos alimentos [44]. Os fungos filamentosos e leveduras são contaminantes comuns em sucos de frutas e representam uma grande preocupação para a indústria [15].

A contagem inicial de bactérias mesófilas totais e fungos filamentosos e leveduras no suco recém-extraído foi de 2,04 e 2,82 Log UFC/mL, respectivamente. Não foi detectada a presença de bactérias ácido-láticas no suco de caju in natura. A baixa contagem microbiana pode ser atribuída à eficácia do processo de higienização dos pedúnculos, uma vez que esse processo pode reduzir a carga microbiana presente na casca, considerada o principal veículo de contaminação do suco. 
A Figura 3 apresenta os resultados da contagem microbiana nas amostras de suco de caju mantidas por $24 \mathrm{~h}$ em diferentes temperaturas. Durante o armazenamento em temperatura ambiente houve um aumento de 3,5 e 3,4 Log UFC/mL da população de bactérias mesófilas totais e de fungos filamentosos e leveduras, respectivamente. Nas amostras refrigeradas as contagens permaneceram constantes. Para as amostras congeladas, foi observada uma redução de 0,46 Log UFC/mL na contagem de fungos filamentos e leveduras e um aumento de 0,44 Log UFC/mL na contagem de bactérias mesófilas totais.

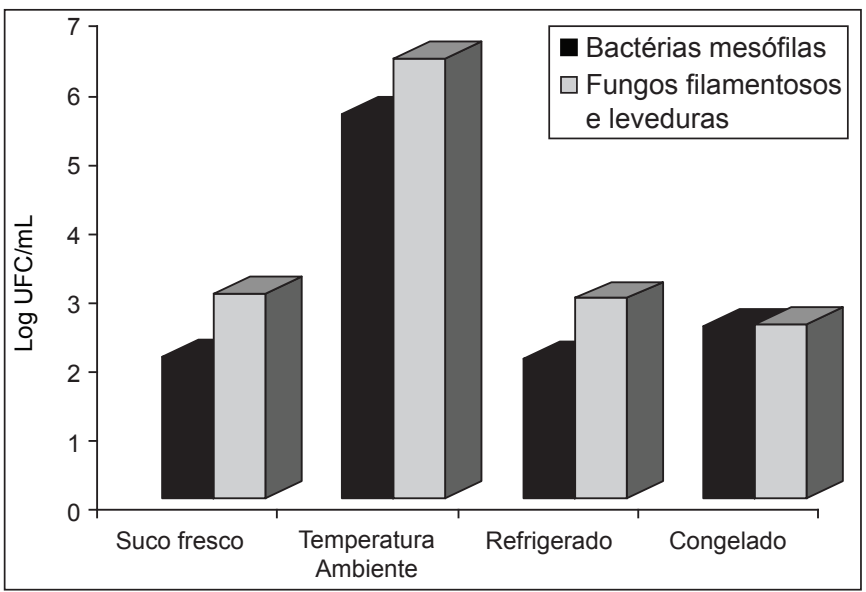

FIGURA 3 - Contagem de bactérias mesófilas totais e de fungos filamentos e leveduras em suco de caju in natura mantido em temperatura ambiente e armazenado sob refrigeração e sob congelamento por $24 \mathrm{~h}$.

A Figura 4 apresenta os resultados da contagem microbiana em amostras de suco de caju mantidas sob refrigeração durante sete dias. Foi observado aumento na contagem de fungos filamentosos e leveduras de, aproximadamente, 1,5 ciclos logarítmicos, enquanto a contagem de bactérias mesófilas totais reduziu aproximadamente 1,0 Log UFC/mL. SADLER et al. [40] observaram estabilidade na contagem de fungos filamentosos e leveduras em suco de laranja durante sete dias de armazenamento a $4{ }^{\circ} \mathrm{C}$.

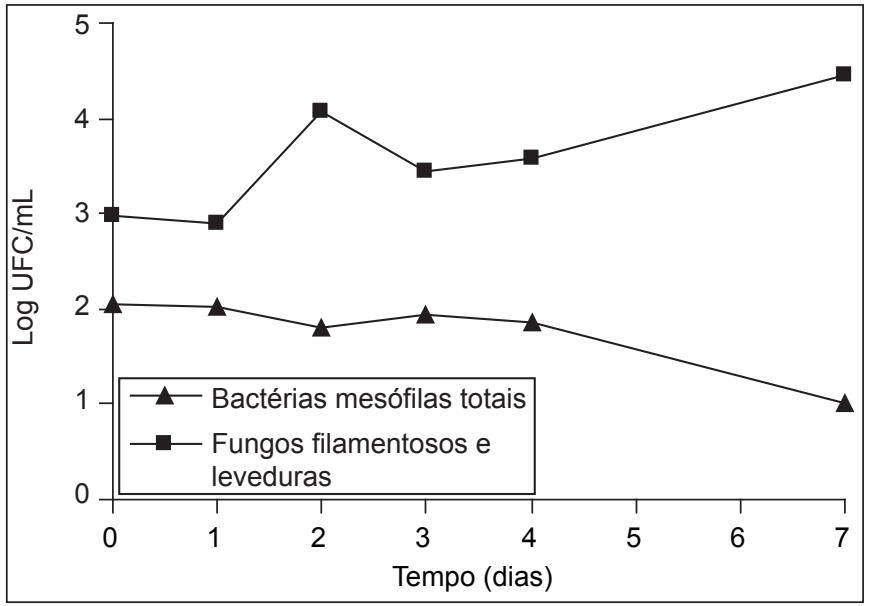

FIGURA 4 - Contagem de bactérias mesófilas totais e de fungos filamentosos e leveduras em suco de caju in natura armazenado sob refrigeração durante sete dias.
A Figura 5 apresenta os resultados da contagem microbiana em suco de caju in natura mantido sob congelamento durante 120 dias. Nestas amostras, houve uma redução progressiva da contagem de fungos filamentosos e leveduras de aproximadamente um ciclo logarítmico até o trigésimo dia, mantendo-se estável até 120 dias. Houve redução na contagem de bactérias mesófilas totais até sete dias. A partir de então, o número de células aumentou até o trigésimo dia, permanecendo estável em 0,61 ciclos logarítmicos acima da contagem inicial até o final do período de análise. A redução microbiana observada inicialmente no suco congelado pode ser justificada pela baixa temperatura, que torna as reações químicas e enzimáticas e o crescimento bacteriano mais lentos. O aumento de mesófilos totais após sete dias de congelamento provavelmente se deve à presença de microrganismos selecionados e adaptados à baixa temperatura.

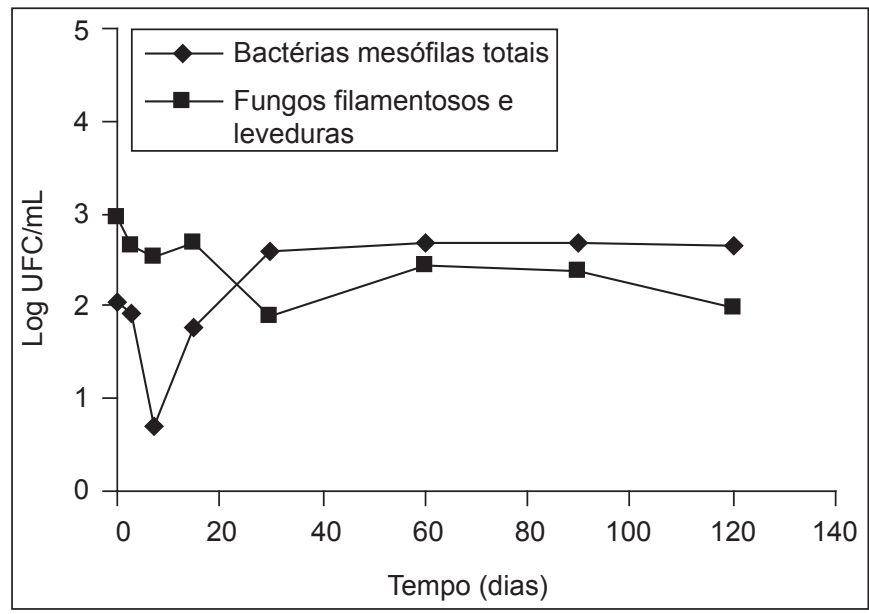

FIGURA 5 - Contagem de bactérias mesófilas totais e de fungos filamentosos e leveduras em suco de caju in natura armazenado sob congelamento $\left(-22^{\circ} \mathrm{C}\right)$ durante 120 dias.

Analisando os parâmetros físico-químicos, observase que o crescimento microbiano não foi suficiente para promover mudanças nos valores de $\mathrm{pH}$ e de acidez do suco de caju armazenado em diferentes tempos e condições de estocagem.

É importante ressaltar que existe uma carência de trabalhos que estudem tanto o perfil quanto a estabilidade microbiológica do suco de caju in natura em diferentes formas e períodos de estocagem. Este fato dificultou a comparação de nossos resultados com a literatura disponível.

\section{4 - CONCLUSÕES}

- O suco de caju in natura apresentou alto teor de AA, sendo uma porção o suficiente para suprir os valores de referência de ingestão diária para diferentes faixas etárias, estados fisiológicos e sexos;

- A redução do teor de AA nos sucos mantidos em temperatura ambiente por 24 h e estocados sob refrigeração por sete dias ou sob congelamento por 120 dias foi de, no máximo, $8,12 \%$. A taxa de redução do teor de 
AA foi menor para o suco congelado do que para o refrigerado;

- O teor de sólidos solúveis totais, a acidez total titulável e o pH do suco de caju mantiveram-se estáveis durante todo período estudado;

- Foi observado aumento superior a três ciclos logarítmicos na contagem de bactérias mesófilas totais e fungos filamentosos e leveduras no suco mantido em temperatura ambiente por $24 \mathrm{~h}$;

- Nos sucos estocados sob refrigeração por sete dias, houve redução de aproximadamente 1,0 ciclo logarítmico na contagem de bactérias mesófilas totais e aumento de 1,5 ciclos logarítmicos na contagem de fungos filamentosos e leveduras;

- Em sucos congelados por 120 dias, a contagem de fungos filamentosos e leveduras permaneceu inferior àquela observada imediatamente após sua extração. A contagem de bactérias mesófilas totais permaneceu constante a partir do trigésimo dia de armazenamento.

\section{5 - REFERÊNCIAS BIBLIOGRÁFICAS}

[1] AKINWALE, T. O. Cashew apple juice: its use in fortifying the nutritional quality of some tropical fruits. European Food Research and Technology, Heidelberg, v. 211 , n. 3, p. 205-207, Aug, 2000.

[2] AKINWALE, T. O.; OLUBAMIWA, O.; AJAV, E. A. Cottage processing of cashew apple juice in Nigeria: physico-chemical and sensory evaluation of product. The Journal of Food Technology in Africa, Nairobi, v. 6, n. 2, p. 56-58, Apr-June, 2001.

[3] ALMEIDA, C. A. N.; CROTT, G. C.; RICCO, R. G.; DEL CIAMPO, L. A.; DUTRA-DE-OLIVEIRA, J. E.; CANTOLINI, A. Control of iron-deficiency anemia in Brazilian preschool children using iron-fortified orange juice. Nutrition Research, v. 23, n. 1, p. 27-33, Jan, 2003.

[4] ALMEIDA, R. B.; GUIMARÃES, R. P.; CASTRO, R. E. S.; PINHEIRO, M. S.; ARAÚJO, K. G. L.; VERRUMA-BERNARDI, M. R. Estudo microbiológico e físico-químico do suco de laranja fresco comercializado em Niterói -RJ. In: Congresso Brasileiro de Ciência e Tecnologia de Alimentos, XVIII., 2002, Rio Grande do Sul. Anais... Rio Grande do Sul, 2002, CD-ROOM.

[5] ALVES, R. E. Características das frutas para exportação. In: NETTO, A. G.; ARDITO, E. F. G.; GARCIA, E. E. C. G.; BLEINROTH, E. W.; FREIRE, F. C. O.; MENEZES, J. B.; BORDINI, M. R.; SOBRINHO, R. B.; ALVES, R. E. Acerola para exportação: procedimentos de colheita e pós-colheita. MAARA/SDR - Brasília: EMBRAPA - SPI, 1996, $30 \mathrm{p}$.

[6] ASSOCIATION OF OFFICIAL ANALYTICAL CHEMISTRY. Official Methods of Analysis. 14. ed. Washington, DC, 1984. $16 \mathrm{p}$.

[7] ASSUnÇÃO, R. B. \& MERCADANTE, A. Z. Carotenoids and ascorbic acid from cashew apple (Anacardium occidentale, L.): a variety and geographic effects. Food Chemistry, v. 81, n. 4, p. 495-502, June, 2003.
[8] BELITZ, H.D. \& GROSCH, W. Química de los alimentos. $2^{\mathrm{a}}$ ed.; Editorial Acribia. Zaragoza. España, 1997. $1087 \mathrm{p}$.

[9] BENASSI, M. T. \& ANTUNES, A. J. A comparison of the metaphosphoric and oxalic acids as extractants solutions for the determination of vitamin $\mathrm{C}$ in selected vegetables. Arquivos de Biologia e Tecnologia, Curitiba, v. 31, n. 4, p. 507-513, Dec, 1988.

[10] BRACKETT, R. E. \& SPLITTSTOESSER, D. F. Fruits and. vegetables. In: VANDERZANT, C., SPLITTSTOESSER, D. F. Compendium for the Microbiological Examination of Foods. $3^{\text {rd }}$ ed. Washington DC: American Public Health Association, 1992. p. 919-927.

[11] BRASIL, RDC n ${ }^{\circ} 12$, de 02/01/2001. Estabelece regulamento técnico sobre os padrões microbiológicos para alimentos. Disponível: http://www.anvisa.org. br/... Acesso em 10 dez. 2005.

[12] CAMPELO, E. C. S.; MARTINS, M. H. B.; CARVALHO, I. T.; PEDROSA, E. M. R. Teores de vitamina C em polpas de acerola (Malpighia glabra L.) congeladas. Boletim CEPPA, Curitiba, v. 16, n. 1, p. 107-113, Jan-June, 1998.

[13] CHAVES, J. B. P. Noções de microbiologia e conservação de alimentos. Viçosa: UFV, 1993. 113p.

[14] CORREA-NETO, R. S.; FARIA, J. A.F. Fatores que influem na qualidade do suco de laranja. Ciência e Tecnologia de Alimentos, Campinas, v. 19, n. 1, p. 153-160, JanApr, 1999.

[15] DAVENPORT, R. Forensic microbiology for soft drinks business. Soft Drinks Management International, London, v. 4, p. 31-32, Nov, 1996.

[16] Dietary Reference Intakes: Applications in dietary assessment 2001. National Academy Press 71-72. $<$ http://www.nap.edu>. Acesso em $17 \mathrm{dez} .2002$.

[17] FIGUEIREDO, R. W.; LAJOLO, F. M.; ALVES, R. E.; FILGUEIRAS, H. A. C. Physical - chemical changes in early dwarf cashew pseudofruits during developments and maturation. Food Chemistry, v. 77, n. 3, p. 343-347, June, 2002.

[18] FRANCO, B. D. G. M. \& LANDGRAF, M. Microbiologia dos Alimentos. 1.ed., Rio de Janeiro: Atheneu, 1996. $182 \mathrm{p}$.

[19] GOMES, P. M. A., FIGUEIRÊDO, R. M. F., QUEIROZ, A.J.M. Caracterização e isotermas de adsorção de umidade da polpa de acerola em pó. Revista Brasileira de Produtos Agroindustriais, Campina Grande, v. 4, n. 2, p. 157-165, 2002.

[20] HERNÁNDEZ, Y.; LOBO, M. G., GONZÁLEZ, M. Determination of vitamin $\mathrm{C}$ in tropical fruits: A comparative evaluation of methods. Food Chemistry, v. 96, n. 4, p. 654-664, June, 2005.

[21] INSTITUTO ADOLF LUTZ. Normas Analíticas do Instituto Adolf Lutz: métodos químicos e físicos para análise de alimentos. 3. ed., São Paulo, 1985, v. 1, $533 \mathrm{p}$.

[22] INYANG, U. E.; ABAH, U. J. Chemical composition and organoleptic evaluation of juice from steamed cashew apple blended with orange juice. Plant Foods for Human Nutrition, v. 50, n. 4, p. 295-300, Dec, 1997. 
[23] JOHNSTON, C. S.; HALE, J. C. Oxidation of ascorbic acid in stored orange juice is associated with reduced plasma vitamin C concentrations and elevated lipid peroxidases. Journal of the American Dietetic Association, Illinois, v. 105, n. 1, p. 106-109, Jan. 2005.

[24] KABASAKALIS, V.; SIOPIDOU, D.; MOSHATOU, E. Ascorbic acid content of commercial fruit juices and its rate of loss upon storage. Food Chemistry, v. 70, n. 3, p. 325-328, Aug. 2000.

[25] LAPPONI, J. C. Estatística usando o Excel. 1. ed. São Paulo: Lapponi Treinamento e Editora, 2000. 450 p.

[26] LEE, H. S. \& COATES, G. A. Vitamin C in frozen, fresh squeezed, unpasteurized, polyethylene-bottled orange juice: a storage study. Food Chemistry, v. 65, n. 2, p. 165-168, May 1999.

[27] MAIA, G. A. Aproveitamento Industrial do Caju (Anacardium occidentale): relatório final. Fortaleza: NUTEC, 1988. $44 \mathrm{p}$.

[28] MAIA, G. A.; MONTEIRO, J. C. S.; GUIMARÃES, A.C.L. Estudo da estabilidade físico-química e química do suco de caju com alto teor de polpa. Ciência e Tecnologia dos Alimentos, Campinas, v. 21, n. 1, p. 43-46, JanApr, 2001.

[29] MAIA, G. A; SOARES, J. B. Gradientes de acidez, açúcares e ácido ascórbico no caju. Boletim Cearense de Agronomia, Fortaleza, v. 11, p. 25-29, 1970.

[30] MUDAMBI, S. R.; RAJAGORPAL, M. V. Vitamin C content of fruits grown in Nigéria. Journal of Food Technology, v. 12 , n. 5, p. 189-191, 1977.

[31] MUSSER, R. S.; LEMOS, M. A.; LIMA, V. L. A. G.; MÉLO, E. A.; LEDERMAN, I. E.; SANTOS, V. F. Características físico-quimicas de acerola da banco ativo germoplasma em Pernambuco. Ciência e Tecnologia de Alimentos, Campinas, v. 24, n. 4, p. 556-561, Oct-Dec, 2004.

[32] NAGY, S. \& SMOOT, J. M. Temperature and storage effects on percent retention and percent U.S. recommend dietary allowance of vitamin $\mathrm{C}$ in canned single-strength orange juice. Journal of Agricultural and Food Chemistry, Washington DC, v. 25, n. 1, p. 135-138, 1977.

[33] OLIVEIRA, J. J. V.; TOLEDO, M. C. F.; SIGRIST, J. M. M.; YOTSUYANAGI, K.; ATHIÉ, I. Avaliação da qualidade de laranja pêra após armazenamento com etileno. Boletim CEPPA, Curitiba, v. 20, n. 2, p. 363-373, JulyDec, 2002.

[34] OLIVEIRA, M. E. B., BASTOS, M. S. R., FEITOSA, T., BRANCO, M. A. A. C., SIlVA, M. G. G. Avaliação de parâmetros de qualidade físico-químicos de polpas congeladas de acerola, cajá e caju. Ciência e Tecnologia de Alimentos, Campinas, v. 19, n. 3, p. 326-332, Sept-Dec, 1999.

[35] OZKAN, M.; KIRCA, A.; CEMEROGLU, B. Effects of hydrogen peroxidase on the stability of ascorbic acid during storage in various fruit juices. Food Chemistry, v. 88, n. 4, p. 591-597, Dec, 2004.

[36] PADULA, M. \& RODRIGUEZ-AMAYA, D. B. Characterization of the carotenoids and assessment of the vitamin A value of Brazilian guavas (Psidium guajava L.). Food Chemistry, v. 20, n. 1, p. 11-19, Jan, 1986.
[37] PAIVA, F. F. A.; GARRUTI, D. S.; SILVA NETO, R. M. Aproveitamento Industrial do caju. Fortaleza: EMBRAPA - Agroindústria Tropical, 85 p. 2000.

[38] PARLAMENTO EUROPEU E CONSELHO (1995). Norma $\mathrm{n}^{\circ}$ 95/2/CE, de 20 de fevereiro de 1995, relativa aos aditivos alimentares com exceção dos corantes e dos edulcorantes. Disponível em: http://europa.eu.int/eurlex/en/consleg/main/1995/en_1995L0002 index.html. Acesso: 12 jan. 2005 .

[39] PEDRÃO, M. R, BELEIA, A, MODESTA, R. C. D., PRUDENCIO-FERREIRA, S. H. Estabilidade físico-química e sensorial do suco de limão Tahiti natural e adoçado, congelado. Ciência e Tecnologia de Alimentos, Campinas, v. 19, n. 2, p. 282-286, May-Aug, 1999.

[40] SADLER, G. D.; PARISH, M. E.; WICKER, L. Microbial, enzymatic, and chemical changes during storage of fresh and processed orange juice. Journal of Food Science, Chicago, v. 57, n. 5, p. 1187-1191, Oct, 1992.

[41] SELli, S.; CABAROGLU, T.; CANBAS, A. Volative flavour components of orange juice obtained from the cv. Kozan of Turkey. Journal of Food Composition and Analysis, v. 17, n. 6, p. 789-796, Dec, 2004.

[42] SILVA, N.; JUNQUEIRA, V. C. A.; SIlVEIRA, N. F. A. Manual de métodos de análise microbiológica de alimentos. São Paulo: Varela, 1997. 259 p.

[43] SILVA, P. T. Estabilidade química e microbiológica do suco de laranja (Citrus Sinensis, Osbeck), cultivar pêra, submetida a diferentes tipos de processamento e condiçóes de estocagem. Rio de Janeiro, 2005, 95 p. Dissertação (Mestrado em Nutrição), Instituto de Nutrição, Universidade Federal do Rio de Janeiro.

[44] SIQUEIRA, R. S. Manual de microbiologia de alimentos. Rio de Janeiro: EMBRAPA, CTAA, 1995. 195 p.

[45] SOARES, C. L.; OLIVEIRA, G. S. F.; MAIA, G. A.; MONTEIRO, J. C. S.; JUNIOR, A. S. Obtenção de bebida a partir de suco de caju (Anacardium occidentale, L.) e extrato de guaraná (Paullina cupana sorbilis Mart. Ducke). Revista Brasileira de Fruticultura, Jaboticabal, v. 23, n. 2, p. 387-390, Aug, 2001.

[46] SOUZA FILHO, M. S.; LIMA, J. R.; SOUZA, A. C. R.; SOUZA NETO, M. A.; COSTA, M. C. Efeito do branqueamento, processo osmótico, tratamento térmico, e armazenamento na estabilidade da vitamina $\mathrm{C}$ de pedúnculos de caju processados por métodos combinados. Ciência e Tecnologia dos Alimentos, Campinas, v. 19, n. 2, p. 211-213, May-Aug, 1999.

[47] TELLES, P. R. S. Estudo do processamento de caju (Anacardium occidentale L.). Campinas, 1974, 45 p. Dissertação (Mestrado em Tecnologia de Alimentos), Faculdade de Engenharia de Alimentos, Universidade Estadual de Campinas.

[48] TREVAS FILHO, V. Tecnologia de produtos do pedúnculo do caju. Fortaleza, I Semana do caju, 1971. 101 p. Apud: Bernhardt \& Hashizume (1978).

[49] VEIGA, B. S.; SILVA, P. T.; LAVINAS, F. C.; LOPES, M. L. M.; VALENTE-MESQUITA, V. L. Estudo da estabilidade do ácido ascórbico em sucos de três cultivares de limão (citrus limon) em diferentes temperaturas de estocagem. In: Congresso Brasileiro de Ciência e Tecnologia de Alimentos, XIX., Anais... Recife, 2004, CD-ROOM. 
[50] WHITFIELD, F. B. Microbiology of food taints. International Journal of Food Science and Technology, v. 33, n. 1, p. 31-51, Feb, 1998.

[51] ZERDIN, K.; ROONEY, M. L.; VERMUE, J. The vitamin $\mathrm{C}$ content of orange juice packed in an oxygen scavenger material. Food Chemistry, v. 82, n. 3, p. 387-395, Aug, 2003.

\section{6 - AGRADECIMENTOS}

À Fundação de Amparo à Pesquisa do Estado do Rio de Janeiro (FAPERJ) pelo apoio financeiro. 